\title{
Mechanochemical synthesis of poly(trimethylene carbonate)s: an example of rate acceleration
}

\author{
Sora Park and Jeung Gon Kim*
}

\author{
Full Research Paper \\ Address: \\ Department of Chemistry and Research Institute of Physics and \\ Chemistry, Chonbuk National University, Jeon-Ju, Jeollabuk-do, \\ 54896, Republic of Korea \\ Email: \\ Jeung Gon Kim - jeunggonkim@jbnu.ac.kr \\ * Corresponding author \\ Keywords: \\ aliphatic polycarbonate; green polymerization; mechanochemistry; \\ organocatalyst; poly(trimethylene carbonate)
}

Beilstein J. Org. Chem. 2019, 15, 963-970.

doi:10.3762/bjoc. 15.93

Received: 28 January 2019

Accepted: 11 April 2019

Published: 23 April 2019

This article is part of the thematic issue "Mechanochemistry II".

Guest Editor: J. G. Hernández

(c) 2019 Park and Kim; licensee Beilstein-Institut. License and terms: see end of document.

\begin{abstract}
Mechanochemical polymerization is a rapidly growing area and a number of polymeric materials can now be obtained through green mechanochemical synthesis. In addition to the general merits of mechanochemistry, such as being solvent-free and resulting in high conversions, we herein explore rate acceleration under ball-milling conditions while the conventional solution-state synthesis suffer from low reactivity. The solvent-free mechanochemical polymerization of trimethylene carbonate using the organocatalysts 1,8-diazabicyclo[5.4.0]undec-7-ene (DBU) and 1,5,7-triazabicyclo[4.4.0]dec-5-ene (TBD) are examined herein. The polymerizations under ball-milling conditions exhibited significant rate enhancements compared to polymerizations in solution. A number of milling parameters were evaluated for the ball-milling polymerization. Temperature increases due to ball collisions and exothermic energy output did not affect the polymerization rate significantly and the initial mixing speed was important for chain-length control. Liquid-assisted grinding was applied for the synthesis of high molecular weight polymers, but it failed to protect the polymer chain from mechanical degradation.
\end{abstract}

\section{Introduction}

Nowadays mechanochemical syntheses are widespread in many areas of chemistry [1-4]. The efficient mixing and energy input induced by mechanical motions have promoted many chemical reactions with superior efficiencies [5]. Sometimes, unexpected outcomes that cannot be achieved by solution synthesis occur, which makes mechanochemistry a topic of rigorous research [6].
In the area of polymer chemistry, the use of mechanical forces has a long history. Strong mechanical forces can break covalent bonds, including strong $\mathrm{C}-\mathrm{C}$ bonds, thus their utilization has generally focused on destructive approaches [7-9]. Recently, along with rapid progress in mechanochemical small molecule syntheses, the constructive polymeric material synthesis also succeeded. In 2014, Swager and co-workers demonstrated that 
poly(phenylene vinylene) could be obtained without any solvent after brief ball milling of monomer and base [10]. The remarkable reactivity exemplified that the general concepts of mechanochemical synthesis are applicable to polymerization reactions. Other examples of polymer syntheses have followed. The Borchardt research team reported the efficient mechanochemical synthesis of poly(azomethine) and poly(phenylene) $[11,12]$. Our group also contributed to this area by developing a ball-milling promoted high-molecular weight poly(lactic acid) synthesis $[13,14]$ and a solvent-free post-polymerization modification of functional polystyrenes [15]. The Friščić team also showed that poly(ethylene oxide) end group modification is facile under ball-mill conditions [16]. Network polymeric material fabrications were also realized using ball milling [17-19].

As mentioned, many mechanochemical reactions realized exceptional efficiencies that solution synthesis cannot afford $[5,20]$. Chemical transformations at maximum concentrations benefit from no dilution, which results in fast conversions, as long as efficient mixing is provided. We envisioned that polymerization systems with low propagation efficiencies under solution conditions could be accelerated through mechanochemical ball milling. The organocatalytic polymerization of trimethylene carbonate to form aliphatic polycarbonates was found to be more efficient when using a mechanical ball-milling reaction than a solution polymerization (Scheme 1). The detailed findings are disclosed in this article.

\section{Results and Discussion}

Aliphatic polycarbonates are found in many biomedical applications since they have many desirable properties such as high biocompatibility, easy degradation, good mechanical properties, and low toxicity [21-23]. Many synthetic methods have been developed, and the chain-growth ring-opening polymerization of cyclic carbonates, such as trimethylene carbonate (TMC) and its derivatives have been used for the controlled synthesis of high-molecular weight polymers. Among many catalysts, organocatalysts have attracted considerable attention, since the use of nontoxic catalysts warrants a safe use in biomedical applications [24].

The amidine base 1,8-diazabicyclo[5.4.0]undec-7-ene (DBU) is one of the best studied and most popular organocatalysts for ring-opening polymerizations of cyclic carbonates and lactones [25-27]. In contrast to the high activity of lactone polymerization, cyclic carbonate polymerization usually requires long reaction times to achieve high conversions (Table 1) [27]. The DBU-catalyzed polymerization of trimethylene carbonate in chloroform, tetrahydrofuran, toluene, and methylene chloride converted less than 5\% monomer into poly(trimethylene carbonate) (PTMC) within $1 \mathrm{~h}$ (Table 1, entries 1-8). It generally took 24 hours to produce PTMCs with over $2,000 \mathrm{~g} / \mathrm{mol}$ number average molecular weights $\left(M_{\mathrm{n}}\right)$. Among the tested solvents, the reaction in $\mathrm{CH}_{2} \mathrm{Cl}_{2}$ was the fastest with $43 \%$ conversion after $24 \mathrm{~h}$ (Table 1, entry 8 ).

The same reaction was conducted using ball milling without any solvent added. All reagents were placed in a $10 \mathrm{~mL}$ stainless-steel milling jar with three $7 \mathrm{~mm}$ diameter stainless-steel balls. The solid-state reaction mixture was placed into a highspeed vibration ball mill. After $30 \mathrm{~min}$ of high-speed vibration (30 Hz), 43\% conversion was recorded, and PTMC with an $M_{\mathrm{n}}$ of $3930 \mathrm{~g} / \mathrm{mol}$ was obtained (Table 1, entry 9), which is comparable to that of PTMC obtained from a $24 \mathrm{~h}$ reaction with $\mathrm{CH}_{2} \mathrm{Cl}_{2}$ (Table 1, entry 8). Longer milling times pushed the reaction to higher degrees of polymerization. A one-hour vibration resulted in $75 \%$ conversion with an $M_{\mathrm{n}}$ of $7380 \mathrm{~g} / \mathrm{mol}$, and the polymerization reached over $90 \%$ conversion after $2 \mathrm{~h}$

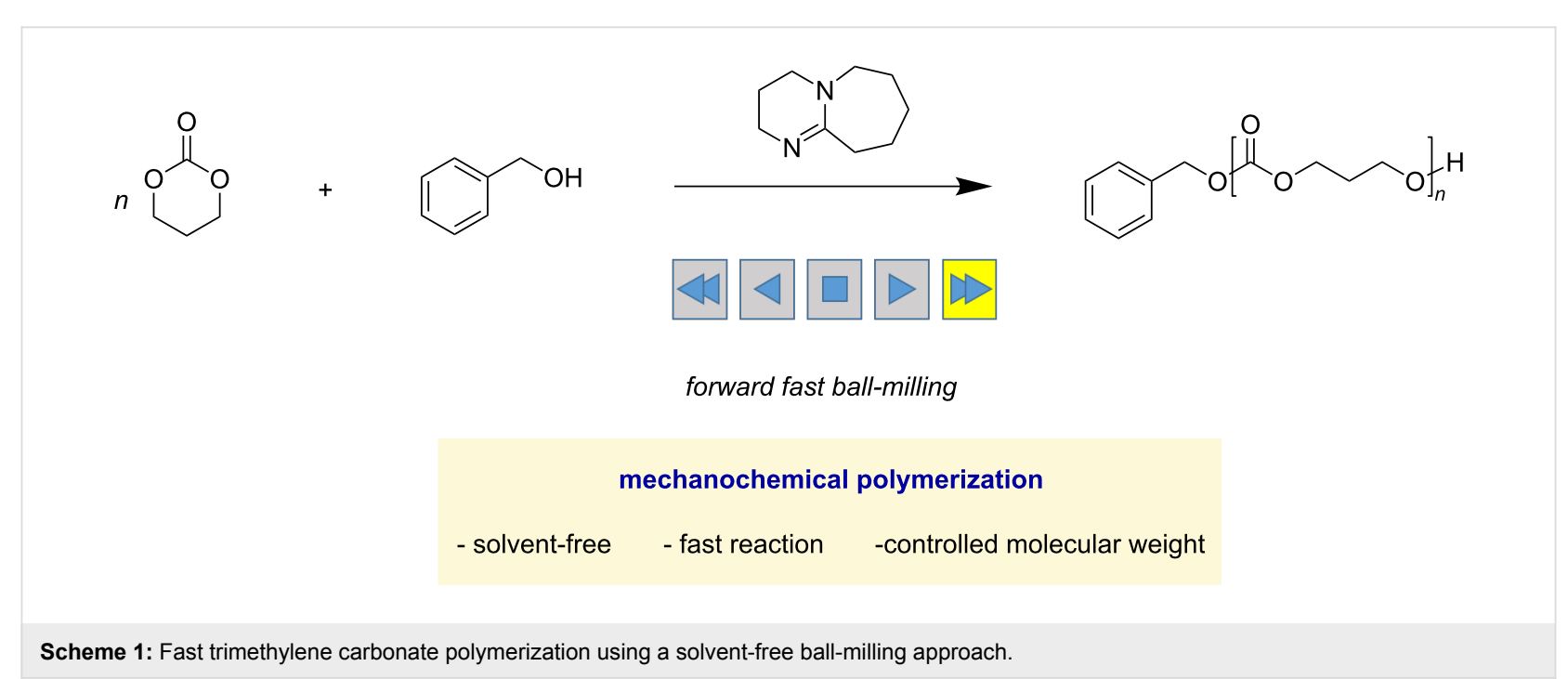


Table 1: DBU-catalyzed polymerization of trimethylene carbonate: solution vs ball milling. ${ }^{\mathrm{a}, \mathrm{b}}$.

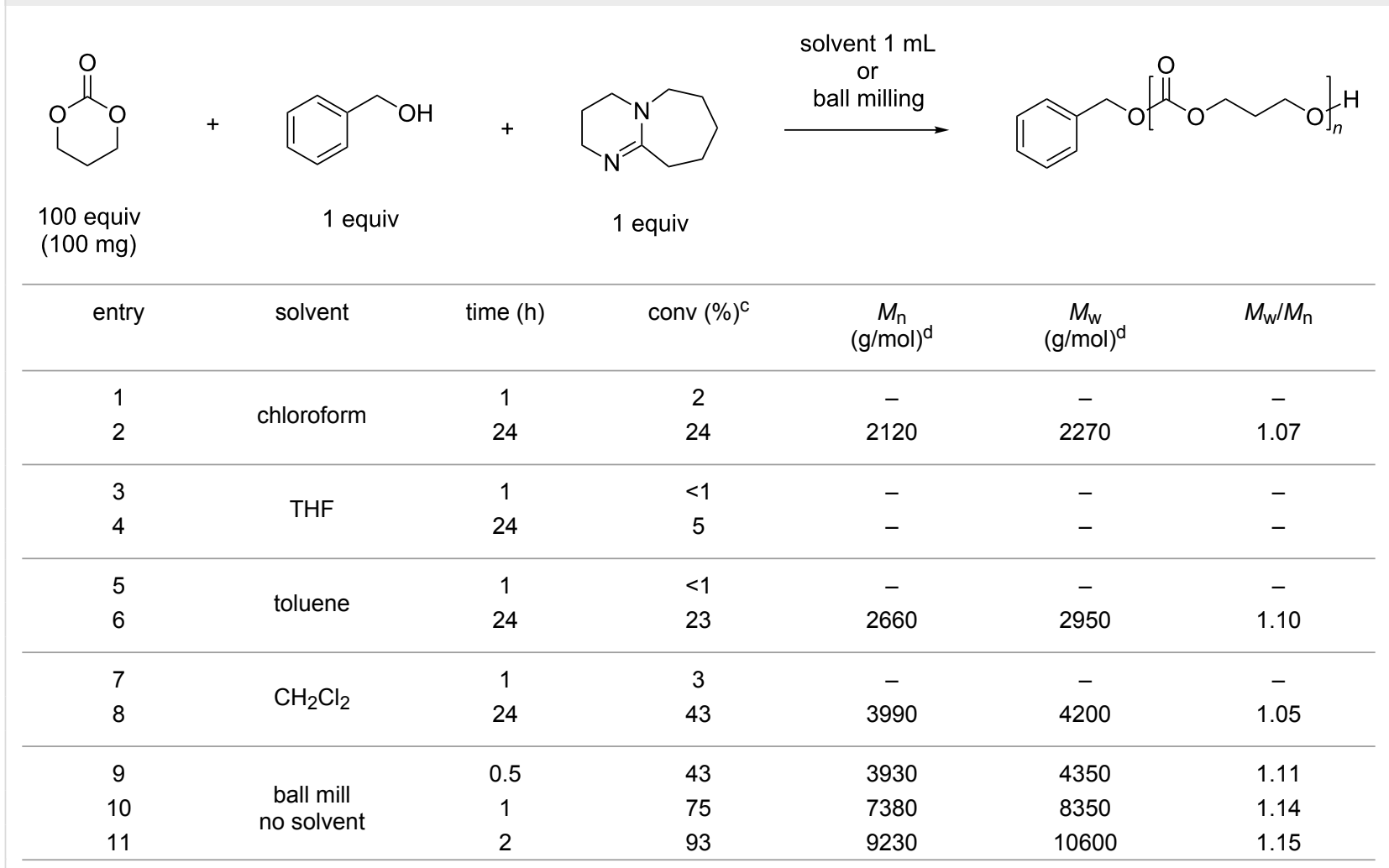

apolymerization conditions: TMC (100 mg, 100 equiv), $\mathrm{BnOH}(1.02 \mu \mathrm{L}, 1$ equiv), and DBU (1.46 $\mu \mathrm{L}, 1$ equiv) in $1 \mathrm{~mL}$ of the selected solvent at rt for the solution reactions, or in a $10 \mathrm{~mL}$ stainless-steel jar with three $7 \mathrm{~mm}$ diameter stainless-steel balls for the ball-milling reactions. ${ }^{\mathrm{b}}$ The average of two runs is reported for the ball-milling reactions. ${ }^{C}$ Determined by ${ }^{1} \mathrm{H}$ NMR spectroscopy. ${ }^{\mathrm{d}}$ Determined by GPC calibrated with polystyrene standards in tetrahydrofuran (THF) at $40^{\circ} \mathrm{C}$.

(Table 1, entries 10 and 11). While the reaction rate was higher than that of the solution reactions, polydispersity under ballmilling conditions remained low $\left(M_{\mathrm{w}} / M_{\mathrm{n}}=1.15\right)$. To maintain low polydispersity, fast initiation and slow propagation are required [28]. In the case of ball-milling polymerization, the time required for the physical mixing of monomer, catalyst, and initiator would result in a delayed initiation of the polymerization. However, the relatively slow propagation rate of DBU-mediated trimethyl carbonate polymerization allowed for well-controlled chain lengths. The previous examples on mechanochemical poly(lactic acid) synthesis resulted in broader molecular weight distributions due to the fast propagation rate $[13,14]$.

Variations of the ball-milling parameters were then scrutinized (Table 2). Firstly, the vibration frequency was varied from $10 \mathrm{~Hz}$ to $30 \mathrm{~Hz}$. Even with the low vibration experiment at $10 \mathrm{~Hz}$ for one hour, $60 \%$ of trimethylene carbonate were converted into the corresponding polymer (Table 2, entry 1 ), which is much faster than conversions observed in solution reactions collected in Table 1. An increase in the vibration frequencies exhibited only a marginal effect. At $20 \mathrm{~Hz}$, only $3 \%$ increase in conversion was observed (63\%, Table 2, entry 2$)$ and at $30 \mathrm{~Hz}$,
$75 \%$ conversion was recorded (Table 2 , entry 3 ). The effect of vibration frequency was found to be less pronounced as in the case of lactide polymerizations [13]. The changes in ball numbers and size were investigated as well, which will increase overall mass of a vibration system. The use of five balls instead of three improved the conversion to $84 \%$ and the vibration with a $12 \mathrm{~mm}$ ball gave $88 \%$ conversion. The mass increase in the vibration system resulted in the improvement of reaction efficiency.

The high impact collision energy [28,29] and exothermic nature of the given ring-opening polymerization [30] could increase the temperature of a ball-mill system, which would speed up the polymerization rate $[31,32]$. To gain insight into thermal effects, we monitored the temperature of the reactor and the reaction mixture (Figure 1). After two hours of high-speed ball milling, the temperature of the reactor and mixture increased to $36{ }^{\circ} \mathrm{C}$. To allow a direct comparison, the solution reactions were also conducted at $40{ }^{\circ} \mathrm{C}$. However, their efficiencies remained far behind those of the ball-milling polymerizations (Table 3 ). In chloroform (Table 3, entries 1 and 2) and toluene (Table 3, entries 5 and 6 ) rate enhancements by thermal energy were ob- 
Table 2: Vibration frequency and ball size and number effects. ${ }^{a, b}$

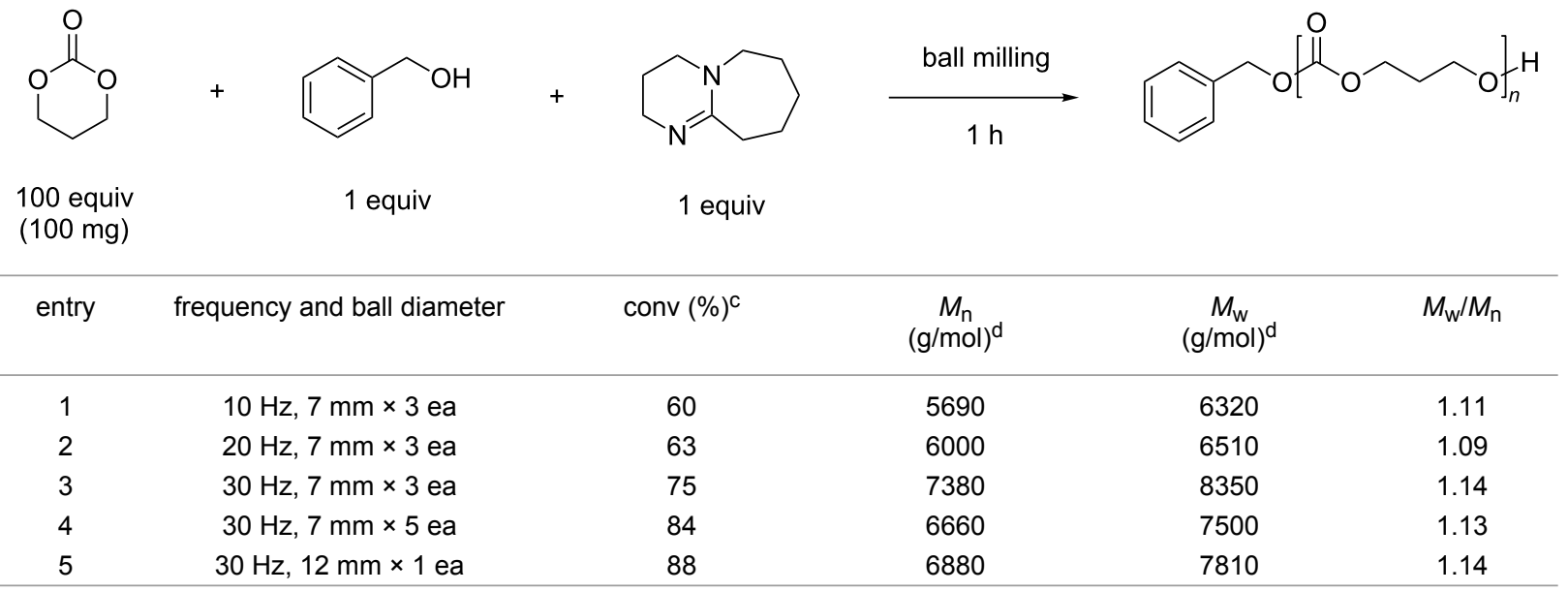

apolymerization conditions: TMC (100 mg, 100 equiv), $\mathrm{BnOH}\left(1.02 \mu \mathrm{L}, 1\right.$ equiv), and DBU (1.46 $\mu \mathrm{L}, 1$ equiv) in a $10 \mathrm{~mL}$ stainless-steel jar. ${ }^{\mathrm{b}}$ The average of the two runs is reported. ${ }^{\mathrm{C}}$ Determined by ${ }^{1} \mathrm{H}$ NMR spectroscopy. ${ }^{\mathrm{d}}$ Determined by GPC calibrated with polystyrene standards in THF at $40{ }^{\circ} \mathrm{C}$.

served, however, their efficiencies remained much lower than that of the ball-milling PTMC synthesis (Table 3, entries 9 and 10). The observed high efficiency of the mechanochemical transformation could originate from a large increase in concentration as well as a temperature difference [5]. In the synthesis of poly(trimethylene carbonate), the observations imply that concentration is a more influential factor than temperature increase for the rate enhancement under ball-milling conditions.
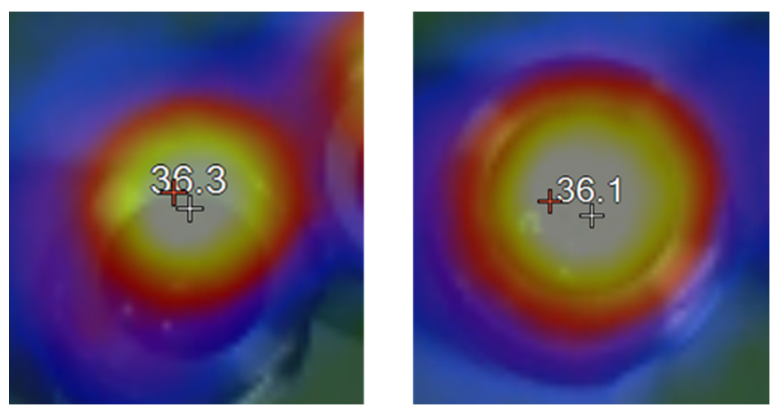

Figure 1: IR thermometer images showing reactor temperatures at the end of the two individual ball-milling reactions (averaged results collected in Table 1, entry 11; individual results, see Supporting Information File 1, left: Table S1, entry 11-1, right: Table S1, entry 11-2).

As another highly reactive organic catalyst, 1,5,7-triazabicyclo[4.4.0]dec-5-ene (TBD) was investigated next. The bicyclic guanidine base TBD has shown better efficiencies than DBU in many chemical transformations including the polymerization of lactides and cyclic carbonates [27,33]. As expected, TBD effectively promoted the polymerization of trimethylene carbonate both, in solution and under solvent-free ball-milling conditions. Nearly quantitative conversions into polymer were achieved within only 5 min (Table 4). Interestingly, TBD-based ball-milling polymerization did not allow for controlling the molecular weight distribution, resulting in a broad polydispersity $\left(M_{\mathrm{w}} / M_{\mathrm{n}}\right)$ of 2.01 (Table 4 , entry 5$)$. As mentioned, fast initiation over chain propagation is one of the requirements in a controlled polymerization. While TBD could chemically enhance both the initiation and propagation steps, the mixing of catalyst, monomer, and initiator by heterogeneous ball milling may physically limit the initiation rate. Thus, a relatively slow initiation process resulted in poor molecular weight control. Most solution polymerizations had no issues with mixing and maintained good molecular weight control. The use of slower polymerization systems is advised for controlled polymerizations under ball-milling conditions.

Next, a high degree of polymerization was pursued. Polymerizations were conducted under the same conditions but with a higher monomer to initiator ratio ([TMC]:[I]:[DBU] = 200:1:2) (Table 5). The reaction reached over $90 \%$ conversion after $3 \mathrm{~h}$. However, the molecular weight did not increase at all. The competitive degradation of poly(trimethyl carbonate) became significant after 100 degrees of polymerization. To validate mechanical degradation of PTMC under ball-milling conditions, high molecular weight PTMC $\left(M_{\mathrm{n}}=22900 \mathrm{~g} / \mathrm{mol}\right)$ was synthesized and grinded under the same mechanical conditions of Table 5, entry 1 , which led to degradation to lower molecular weight $\left(M_{\mathrm{n}}=8220 \mathrm{~g} / \mathrm{mol}\right)$. In our previous study on poly(lactic acid) synthesis, liquid-assisted grinding (LAG), the addition of a very small amount of a liquid, prevented chain-degradation from high impact collisions, and afforded PLA with over $100,000 \mathrm{~g} / \mathrm{mol}$. Thus, LAG was also tested in the PTMC synthesis $[13,14]$ with toluene and THF as liquids. A catalytic 
Table 3: DBU-catalyzed polymerization of trimethylene carbonate at $40^{\circ} \mathrm{C} .^{a}$

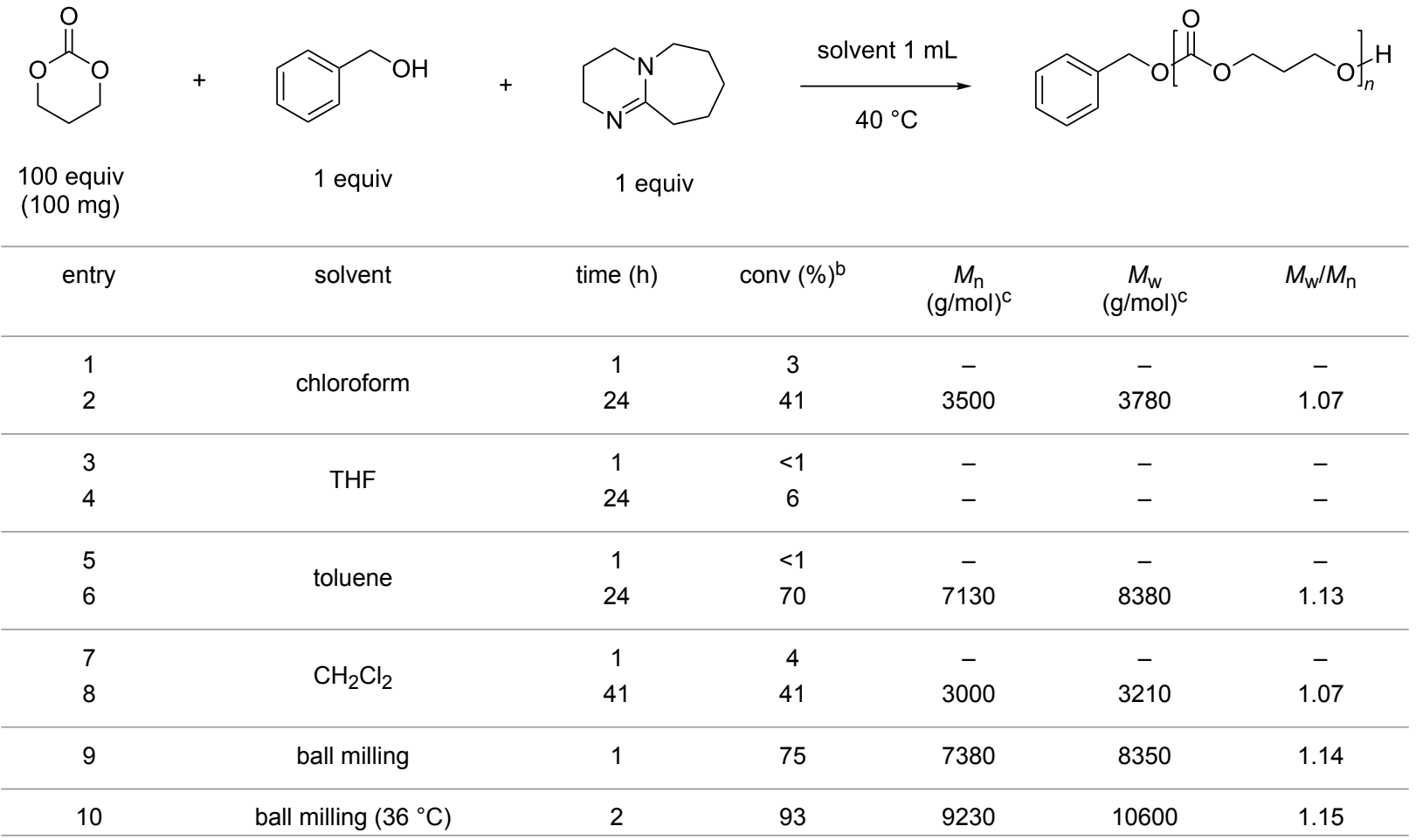

aPolymerization conditions: TMC (100 mg, 100 equiv), $\mathrm{BnOH}\left(1.02 \mu \mathrm{L}, 1\right.$ equiv), and DBU (1.46 $\mu \mathrm{L}, 1$ equiv) in $1 \mathrm{~mL}$ of the selected solvent at $40{ }^{\circ} \mathrm{C}$. ${ }^{b}$ Determined by ${ }^{1} \mathrm{H}$ NMR spectroscopy. ${ }^{\mathrm{C}}$ Determined by GPC calibrated with polystyrene standards in tetrahydrofuran (THF) at $40{ }^{\circ} \mathrm{C}$.

Table 4: TBD-catalyzed polymerization of trimethylene carbonate: solution vs ball milling. ${ }^{\mathrm{a}}$

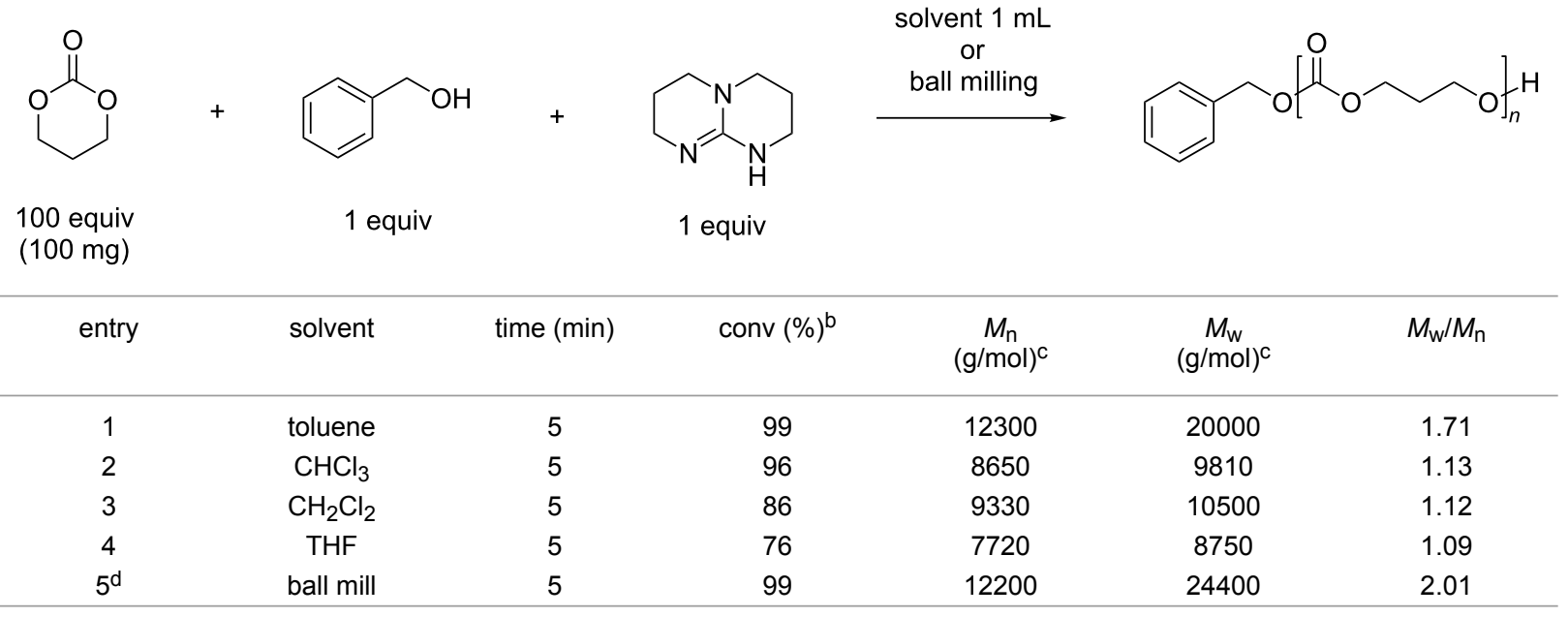

aPolymerization conditions: (solution) TMC (100 mg, 100 equiv), $\mathrm{BnOH}(1.02 \mu \mathrm{L}, 1$ equiv), and TBD (1.4 mg, 1 equiv) in $1 \mathrm{~mL}$ selected solvent at rt; (ball milling) in a $10 \mathrm{~mL}$ stainless-steel jar with three stainless-steel balls with $7 \mathrm{~mm}$ diameter. ${ }^{\mathrm{b}}$ Determined by ${ }^{1} \mathrm{H}$ NMR spectroscopy. ${ }^{\mathrm{c}}$ Determined by GPC calibrated with polystyrene standards in tetrahydrofuran (THF) at $40{ }^{\circ} \mathrm{C}$. ${ }^{\mathrm{d}}$ Average of two runs is reported.

amount of liquid ( 10 or $20 \mu \mathrm{L}$ to $100 \mathrm{mg}$ TMC), however, failed to protect the poly(trimethylene carbonate) chain from mechanical degradation and similar molecular weights were ob- tained, regardless of LAG. The LAG for mechanochemical polymerization reactions has been studied only in limited cases so far and the exact working mechanism is currently obscure. To 
Table 5: PTMC synthesis with a high monomer to initiator ratio. ${ }^{\text {a }}$

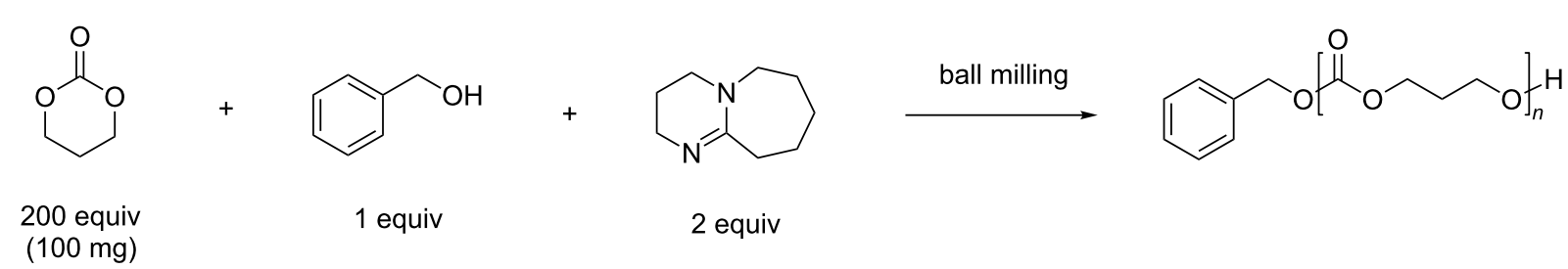

\begin{tabular}{cccccc}
\hline entry & liquid additives & time & conv $(\%)^{\mathrm{b}}$ & $\begin{array}{c}M_{\mathrm{n}} \\
(\mathrm{g} / \mathrm{mol})^{\mathrm{c}}\end{array}$ & $\begin{array}{c}M_{\mathrm{w}} \\
(\mathrm{g} / \mathrm{mol})^{\mathrm{C}}\end{array}$ \\
\hline 1 & none & $3 \mathrm{~h}$ & 97 & 10900 & 13600 \\
2 & toluene $(10 \mu \mathrm{L})$ & $3 \mathrm{~h}$ & 86 & 11900 & 13100 \\
3 & toluene $(20 \mu \mathrm{L})$ & $3 \mathrm{~h}$ & 91 & 11500 & 13700 \\
4 & THF $(20 \mu \mathrm{L})$ & $3 \mathrm{~h}$ & 96 & 11400 & 1.10 \\
\hline
\end{tabular}

aPolymerization conditions: TMC (100 mg, 200 equiv), $\mathrm{BnOH}(0.49 \mu \mathrm{L}, 1$ equiv), and $\mathrm{DBU}(1.46 \mu \mathrm{L}, 2$ equiv) in a $10 \mathrm{~mL}$ stainless-steel jar with three $7 \mathrm{~mm}$ diameter stainless-steel balls. ${ }^{b}$ Determined by ${ }^{1} \mathrm{H}$ NMR spectroscopy. ${ }^{C}$ Determined by GPC calibrated with polystyrene standards in tetrahydrofuran (THF) at $40^{\circ} \mathrm{C}$.

have a better understanding of LAG on chain protection, extensive studies are currently in progress.

\section{Conclusion}

A mechanochemical method, ball milling, was applied to the synthesis of poly(trimethylene carbonate). The representative organocatalyst, DBU, exhibited excellent polymerization efficiency and good chain-length control under solvent-free conditions. When compared to the very low rate obtained under solution conditions, this demonstrates that mechanochemical reactions can improve reaction efficiency and greenness. The use of TBD truly enhanced the efficiency, and all polymerizations reached completion within $5 \mathrm{~min}$, despite physical mixing limitations. However, the mechanochemical polymerization was accompanied by degradation processes, which limited the molecular weight to $10,000 \mathrm{~g} / \mathrm{mol}$. Liquid-assisted grinding did not show any protective effect, and the search for other parameters to mitigate polymer-chain breaking is currently in progress.

\section{Experimental}

General considerations. Chemical reagents obtained from commercial sources were used without further purification. 1,8Diazabicyclo[5.4.0] undec-7-ene (DBU) was distilled over $\mathrm{CaH}_{2}$. All solvents (THF, $\mathrm{CH}_{2} \mathrm{Cl}_{2}, \mathrm{CHCl}_{3}$, and toluene) were dried over a mixture of pre-activated neutral alumina and $3 \AA$ molecular sieves. A Retsch Mixer Mill MM 400 was used for the ball-milling experiments with a $10 \mathrm{~mL}$ stainless-steel vessel and $7 \mathrm{~mm}$ stainless balls. ${ }^{1} \mathrm{H}$ NMR spectra were recorded with a $400 \mathrm{MHz}$ Bruker Avance III HD Fourier transform NMR spectrometer and all signals were referenced to residual protonated solvent. Gel permeation chromatography (GPC) analyses with refractive index (RI) detection were used to determine the num- ber-averaged molecular weights $\left(M_{\mathrm{n}}\right)$, weight-averaged molecular weights $\left(M_{\mathrm{W}}\right)$, and polydispersities $\left(M_{\mathrm{w}} / M_{\mathrm{n}}\right)$. The RI measurements were carried out using an instrument set composed of a Waters 1515 isocratic pump, a 2414 differential refractive index detector, and a column-heating module with Shodex KF-804, KF-803, and KF-802.5 columns in series. The columns were eluted with tetrahydrofuran (preservative-free HPLC grade, Fisher) at $40{ }^{\circ} \mathrm{C}$ at $1.0 \mathrm{~mL} / \mathrm{min}$ and calibrated using 14 monodisperse polystyrene standards (Alfa Aesar). The temperature was recorded using a Fluke VT04 Visual IR thermometer.

Synthesis of trimethylene carbonate. 1,3-Propanediol (4.72 $\mathrm{mL}, 0.657 \mathrm{~mol})$ and ethyl chloroformate $(12.5 \mathrm{~mL}$, $0.131 \mathrm{~mol})$ were dissolved in anhydrous THF $(0.13 \mathrm{~L})$. The mixture was stirred in an ice bath for $1 \mathrm{~h}$ and a solution of triethylamine $(19.2 \mathrm{~mL}, 0.138 \mathrm{~mol})$ in THF $(9 \mathrm{~mL})$ was slowly added. Then, the solution was transferred to ambient temperature and stirred for $2 \mathrm{~h}$. The reaction mixture was filtered and the volume of the solution was reduced to $40-50 \mathrm{~mL}$. The mixture was kept in a freezer for $12 \mathrm{~h}$ and the precipitate was recovered by filtration. The recovered solid was recrystallized in ethyl acetate and sublimed (2.9 g, 43\%). ${ }^{1} \mathrm{H}$ NMR (400 MHz, $\left.\mathrm{CDCl}_{3}\right) \delta 4.47-4.44(\mathrm{t}, 4 \mathrm{H}), 2.18-2.12$ (quintet, $2 \mathrm{H}$ ).

\section{Representative procedure for mechanochemical solvent-free} poly(trimethylene carbonate) synthesis (Table 1, entry 11). Three $7 \mathrm{~mm}$ stainless-steel milling balls were placed in a $10 \mathrm{~mL}$ stainless-steel milling container and trimethylene carbonate $(0.100 \mathrm{~g})$, benzyl alcohol $(1.02 \mu \mathrm{L})$, and DBU $(1.46 \mu \mathrm{L})$ were added. The milling vessel was placed in a vibrational ball mill and vibrated at $30 \mathrm{~Hz}$. After 2 hours, the vessel was opened and 
benzoic acid $(10 \mathrm{mg})$ was added followed by an additional 5 minutes of milling to quench the polymerization. To avoid data inconsistency due to inhomogeneity, all material was dissolved in methylene chloride and an aliquot was subjected to analysis by ${ }^{1} \mathrm{H}$ NMR spectroscopy and GPC measurements to determine the conversion and molecular weight.

\section{Supporting Information}

\section{Supporting Information File 1}

Raw data for tables, GPC and NMR spectra.

[https://www.beilstein-journals.org/bjoc/content/ supplementary/1860-5397-15-93-S1.pdf]

\section{Acknowledgements}

This research was supported by the National Research Foundation of Korea (NRF-2012M3A7B4049677).

\section{ORCID ${ }^{\circledR}$ iDs}

Jeung Gon Kim - https://orcid.org/0000-0003-1685-2833

\section{References}

1. James, S. L.; Friščić, T. Chem. Soc. Rev. 2013, 42, 7494-7496. doi:10.1039/c3cs90058d

2. James, S. L.; Adams, C. J.; Bolm, C.; Braga, D.; Collier, P.; Friščić, T.; Grepioni, F.; Harris, K. D. M.; Hyett, G.; Jones, W.; Krebs, A.; Mack, J.; Maini, L.; Orpen, A. G.; Parkin, I. P.; Shearouse, W. C.; Steed, J. W.; Waddell, D. C. Chem. Soc. Rev. 2012, 41, 413-447. doi:10.1039/c1cs15171a

3. Hernández, J. G. Beilstein J. Org. Chem. 2017, 13, 2372-2373. doi:10.3762/bjoc.13.234

4. Do, J.-L.; Friščić, T. ACS Cent. Sci. 2017, 3, 13-19. doi:10.1021/acscentsci.6b00277

5. Howard, J. L.; Cao, Q.; Browne, D. L. Chem. Sci. 2018, 9, 3080-3094. doi:10.1039/c7sc05371a

6. Hernández, J. G.; Bolm, C. J. Org. Chem. 2017, 82, 4007-4019. doi:10.1021/acs.joc.6b02887

7. Li, J.; Nagamani, C.; Moore, J. S. Acc. Chem. Res. 2015, 48, 2181-2190. doi:10.1021/acs.accounts.5b00184

8. Kean, Z. S.; Craig, S. L. Polymer 2012, 53, 1035-1048. doi:10.1016/j.polymer.2012.01.018

9. Chen, Z.; Mercer, J. A. M.; Zhu, X.; Romaniuk, J. A. H.; Pfattner, R.; Cegelski, L.; Martinez, T. J.; Burns, N. Z.; Xia, Y. Science 2017, 357, 475-479. doi:10.1126/science.aan2797

10. Ravnsbæk, J. B.; Swager, T. M. ACS Macro Lett. 2014, 3, 305-309. doi:10.1021/mz500098r

11. Grätz, S.; Borchardt, L. RSC Adv. 2016, 6, 64799-64802. doi:10.1039/c6ra15677k

12. Grätz, S.; Wolfrum, B.; Borchardt, L. Green Chem. 2017, 19, 2973-2979. doi:10.1039/c7gc00693d

13. Ohn, N.; Shin, J.; Kim, S. S.; Kim, J. G. ChemSusChem 2017, 10, 3529-3533. doi:10.1002/cssc.201700873

14. Lee, G. S.; Moon, B. R.; Jeong, H.; Shin, J.; Kim, J. G. Polym. Chem. 2019, 10, 539-545. doi:10.1039/c8py01520a
15. Ohn, N.; Kim, J. G. ACS Macro Lett. 2018, 7, 561-565. doi:10.1021/acsmacrolett.8b00171

16. Malca, M. Y.; Ferko, P.-O.; Friščić, T.; Moores, A. Beilstein J. Org. Chem. 2017, 13, 1963-1968. doi:10.3762/bjoc.13.191

17.Zhu, X.; Tian, C.; Jin, T.; Browning, K. L.; Sacci, R. L.; Veith, G. M.; Dai, S. ACS Macro Lett. 2017, 6, 1056-1059. doi:10.1021/acsmacrolett.7b00480

18. Grätz, S.; Oltermann, M.; Troschke, E.; Paasch, S.; Krause, S.; Brunner, E.; Borchardt, L. J. Mater. Chem. A 2018, 6, 21901-21905. doi:10.1039/c8ta03684e

19. Grätz, S.; Beyer, D.; Tkachova, V.; Hellmann, S.; Berger, R.; Feng, X.; Borchardt, L. Chem. Commun. 2018, 54, 5307-5310. doi:10.1039/c8cc01993b

20. Immohr, S.; Felderhoff, M.; Weidenthaler, C.; Schüth, F. Angew. Chem., Int. Ed. 2013, 52, 12688-12691. doi:10.1002/anie.201305992

21. Dai, Y.; Zhang, X. Polym. Chem. 2017, 8, 7429-7437. doi:10.1039/c7py01815k

22. Xu, J.; Feng, E.; Song, J. J. Appl. Polym. Sci. 2014, 131, 39822. doi:10.1002/app.39822

23. Feng, J.; Zhuo, R.-X.; Zhang, X.-Z. Prog. Polym. Sci. 2012, 37, 211-236. doi:10.1016/j.progpolymsci.2011.07.008

24. Kamber, N. E.; Jeong, W.; Waymouth, R. M.; Pratt, R. C.; Lohmeijer, B. G. G.; Hedrick, J. L. Chem. Rev. 2007, 107, 5813-5840. doi:10.1021/cr068415b

25. Sherck, N. J.; Kim, H. C.; Won, Y.-Y. Macromolecules 2016, 49, 4699-4713. doi:10.1021/acs.macromol.6b00621

26. Nederberg, F.; Lohmeijer, B. G. G.; Leibfarth, F.; Pratt, R. C.; Choi, J.; Dove, A. P.; Waymouth, R. M.; Hedrick, J. L. Biomacromolecules 2007, 8, 153-160. doi:10.1021/bm060795n

27. Lohmeijer, B. G. G.; Pratt, R. C.; Leibfarth, F.; Logan, J. W.; Long, D. A.; Dove, A. P.; Nederberg, F.; Choi, J.; Wade, C.; Waymouth, R. M.; Hedrick, J. L. Macromolecules 2006, 39, 8574-8583. doi:10.1021/ma0619381

28. Andersen, J.; Mack, J. Angew. Chem., Int. Ed. 2018, 57, 13062-13065. doi:10.1002/anie.201805263

29. Kulla, H.; Wilke, M.; Fischer, F.; Röllig, M.; Maierhofer, C.; Emmerling, F. Chem. Commun. 2017, 53, 1664-1667. doi:10.1039/c6cc08950j

30. Matsuo, J.; Aoki, K.; Sanda, F.; Endo, T. Macromolecules 1998, 31 , 4432-4438. doi:10.1021/ma971227q

31. Hutchings, B. P.; Crawford, D. E.; Gao, L.; Hu, P.; James, S. L. Angew. Chem., Int. Ed. 2017, 56, 15252-15256. doi:10.1002/anie.201706723

32. Užarević, K.; Ferdelji, N.; Mrla, T.; Julien, P. A.; Halasz, B.; Friščić, T.; Halasz, I. Chem. Sci. 2018, 9, 2525-2532. doi:10.1039/c7sc05312f

33. Baral, E. R.; Lee, J. H.; Kim, J. G. J. Org. Chem. 2018, 83, 11768-11776. doi:10.1021/acs.joc.8b01695 


\section{License and Terms}

This is an Open Access article under the terms of the Creative Commons Attribution License (http://creativecommons.org/licenses/by/4.0). Please note that the reuse, redistribution and reproduction in particular requires that the authors and source are credited.

The license is subject to the Beilstein Journal of Organic Chemistry terms and conditions:

(https://www.beilstein-journals.org/bjoc)

The definitive version of this article is the electronic one which can be found at:

doi:10.3762/bjoc. 15.93 